\title{
Eastern Equine Encephalitis Virus in Mexican Wolf Pups at Zoo, Michigan, USA
}

\author{
Kimberly A. Thompson, Eileen Henderson, Scott D. Fitzgerald, Edward D. Walker, Matti Kiupel
}

During the 2019 Eastern equine encephalitis virus (EEEV) outbreak in Michigan, two 2-month old Mexican wolf pups experienced neurologic signs, lymphohistiocytic neutrophilic meningoencephalitis with neuronal necrosis and neuronophagia, and acute death. We identified EEEV by reverse transcription real-time $\mathrm{PCR}$ and in situ hybridization. Vector mosquitoes were trapped at the zoo.

Tn North America, Eastern equine encephalitis virus L(EEEV; family Togaviridae, genus Alphavirus) occurs as an enzootic cycle between mosquitoes (primarily Culiseta melanura) and passerine birds within freshwater hardwood swamps (1-3). When favorable ecologic conditions occur, EEEV prevalence increases via amplification until spillover transmission occurs into humans and equids, and less commonly other species (1). Other mosquito species, such as Coquilettidia perturbans and Aedes vexans, act as bridge vectors by preferentially feeding on mammals; they may be responsible for the epizootic cases among mammalian hosts (2). Outbreaks of EEEV in the northern United States occur intermittently between years but during a predictable time of the year, late summer through early fall (3).

Among the naturally occurring encephalitic alphaviruses, EEEV has the highest mortality rate in humans (50\%-75\%) and equids (70\%-90\%) (4). Additional reports exist of clinical disease in a wide variety of mammalian and avian species, including swine, cattle, white-tailed deer, alpacas, seals, domestic canids, pheasants, emus, penguins, and cassowary birds (5-10). Clinical signs of EEEV range from as-

Author affiliations: Binder Park Zoo, Battle Creek, Michigan, USA (K.A. Thompson); Michigan State University Veterinary Diagnostic Laboratory, Lansing, Michigan, USA (E. Henderson, S.D. Fitzgerald, M. Kiupel); Michigan State University Department of Entomology, Lansing (E.D. Walker)

DOI: https://doi.org/10.3201/eid2704.202400 ymptomatic infection to severe and often fatal neurologic disease; signs may include pyrexia, anorexia, recumbency, diarrhea, ataxia, seizures, nystagmus, and head pressing. Previous reports of EEEV in domestic canids have been rare and have mainly been in young puppies $<6$ months of age $(9,10)$. Serologic evidence suggests that exposure to EEEV in free-ranging gray wolves (Canis lupus) is low ( $0 \%$ of pups and $3 \%$ of adults) in Minnesota (11), where EEEV is uncommon.

\section{The Study}

In 2019, the southwest region of Michigan experienced high incidence of EEEV exposure in humans and nonhuman animals, including wild deer and domestic horses $(7,8,12)$. Clinical human cases were reported during June 18-September 20, 2019 (12). Binder Park Zoo (BPZ) (Battle Creek, Michigan, USA) is on a 400 -acre property, half maintained as natural wetlands with a large population of native waterfowl and passerine avian species and half as a developed zoo. The Mexican wolf exhibit is located $\approx 30 \mathrm{~m}$ from the natural wetlands. In the midst of the outbreak, EEEV was diagnosed in two 2-month old Mexican wolf (Canis lupus baileyi) pups at BPZ. We assumed that transmission of EEEV to the wolf pups was from a mosquito bite that occurred at their exhibit location.

Pup 1 was a 2-month-old male pup that was brought for care on September 1, 2019, after a brief entanglement with the exhibit's electric fence. The pup was noted to be increasingly ataxic, which progressed quickly to an obtunded recumbent state. On examination, the pup had decreased responsiveness to handling, increased respiratory effort and crackles, anisocoria, and pyrexia (temperature of $40^{\circ} \mathrm{C}$; in adult domestic canids, pyrexia is $\left.\geq 40^{\circ} \mathrm{C}\right)(9)$. Initial supportive care was unsuccessful; the pup died shortly thereafter. Necropsy revealed a focal area of hemorrhage along the junction of the basilar and posterior cerebral arteries. We submitted formalin-fixed tissues to Michigan State University Veterinary Diagnostic Lab- 


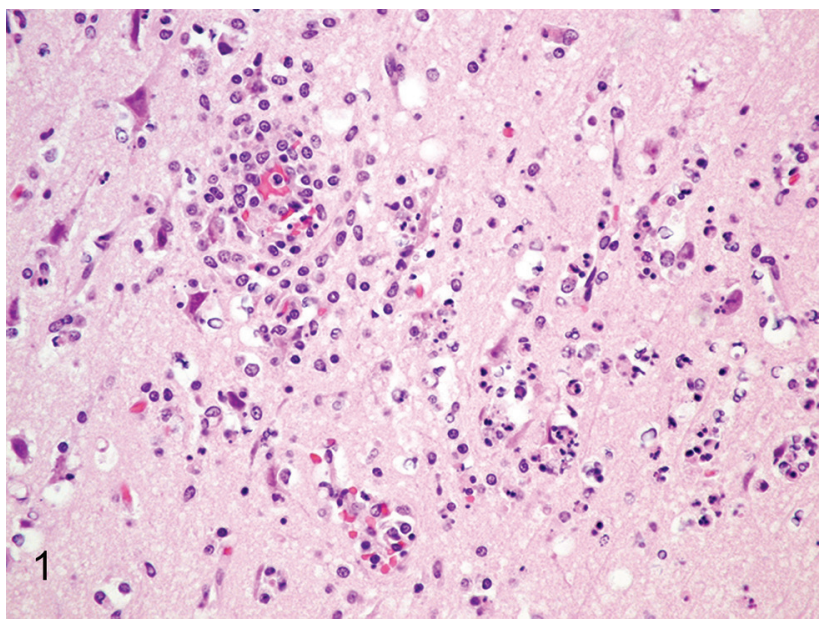

Figure 1. Brain specimen from Mexican wolf pup infected with eastern equine encephalitis virus at Binder Park Zoo, Michigan, USA. Hematoxylin and eosin stain shows severe, acute necrotizing and neutrophilic encephalitis with neuronal necrosis with pyknotic nuclei associated with perineuronal satellitosis and neutrophilic neuronophagia.

oratory (MSU VDL; Lansing, Michigan, USA) for histopathology. Throughout the cerebrum we observed expansion of the Virchow-Robin space by large numbers of lymphocytes and histocytes with extension of the inflammatory cells into the surrounding neuropil. Gray and white matter had randomly scattered foci of rarefaction and necrosis with low numbers of associated infiltrating neutrophils (Figure 1). Inflammatory cells often surrounded and occasionally phagocytize necrotic neurons in the process of neuronophagia. The meninges were expanded by edema and moderate numbers of lymphocytes and histiocytes. The cerebellum and brain stem had similar lesions. The cerebrum was positive for EEEV on SYBR green-based real-time reverse transcription PCR (rRT-PCR); EEEV nucleic acid was detected within neurons via in situ hybridization (Figure 2) $(13,14)$. We noted a mild eosinophilic pneumonia.

Pup 2 was found deceased in the underground den the following day. This male pup had a history of healing traumatic rib fractures and delayed growth rate; he was in treatment for pneumonia and a suspected hepatic abscess and had been improving. Necropsy revealed healed rib fractures and consolidated left cranial lung lobes; the liver was firm, with a pronounced lobular pattern and prominent white interlobular septae. We sent formalinfixed tissues for histopathology at MSU VDL. The lesions within the brain were similar to those described for pup 1. In addition, there was a moderate lymphoplasmacytic bronchointerstitial pneumonia and severe chronic fibrosing periportal hepatitis,

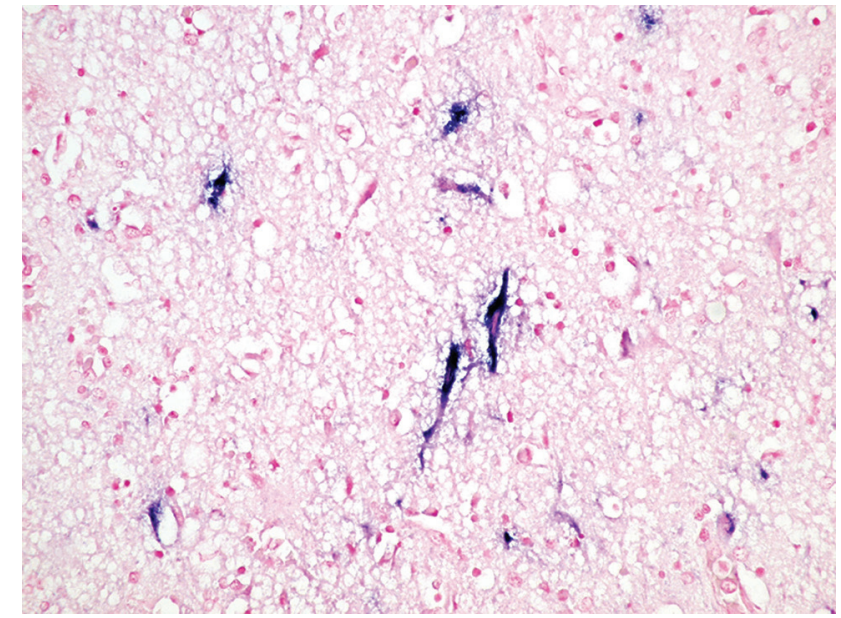

Figure 2. Brain specimen from Mexican wolf pup infected with eastern equine encephalitis virus (EEEV) at Binder Park Zoo, Michigan, USA. Blue stain shows EEEV nucleic acid in the perikaryon and dendrites of necrotic and intact neurons. Nuclear fast red counterstain shows nitro blue tetrazolium/5-Bromo-4chloro-3-indolyl phosphate (NBT/BCIP) chromogen.

moderate bile duct hyperplasia, moderate arteriole proliferation, and intermittent absence of periportal veins (portal vein hypoplasia), most consistent with a congenital vascular anomaly. Culture of the lung was positive for rare Mycoplasma canis and moderate Escherichia coli (negative for virulence factor genes cnf1 and cnf2). The brain was positive by rRT-PCR for EEEV; in situ hybridization detected EEEV nucleic acid $(13,14)$.

The surviving female pup (pup 3) and the dam and sire showed no clinical signs. Banked serum samples frozen at $-30^{\circ} \mathrm{C}$ were sent to National Veterinary Services Laboratories (Ames, Iowa, USA) for plaque reduction neutralization test to evaluate timelines of exposure for pups 1,2, and 3. Samples from pups 2 and 3 were negative, whereas serum from pup 1 tested positive for neutralizing antibodies at 1:10 dilution on the day of death (Table 1). Frozen cerebrum from the fourth littermate (pup 4) that had died a month earlier at 4 weeks of age tested negative by rRT-PCR for EEEV $(13,14)$. Necropsy findings from

\begin{tabular}{lcc}
\hline \multicolumn{3}{l}{ Table 1. Plaque reduction neutralization test results for eastern } \\
equine encephalitis virus in banked serum samples from 3 \\
\multicolumn{3}{l}{ Mexican wolf pups at Binder Park Zoo, Michigan, USA* } \\
\hline Animal ID & Date & Result \\
\hline Pup 1 & 2019 Aug 14 & Negative \\
& 2019 Sep 1 & Positive \\
\hline Pup 2 & 2019 Aug 12 & Negative \\
& 2019 Aug 22 & Negative \\
\hline Pup 3 & 2019 Aug 14 & Negative \\
& 2019 Sep 20 & Negative \\
\hline
\end{tabular}

${ }^{*}$ Test result interpreted at 1:10. Pups were tested before (all pups), during (pup 2), and after (pup 3 only) an outbreak of eastern equine encephalitis. 
Table 2. Results from 3 rounds of mosquito trapping at Binder Park Zoo, Michigan, USA*

\begin{tabular}{|c|c|c|c|}
\hline \multirow[b]{2}{*}{ Mosquito species } & \multicolumn{3}{|c|}{ Trap date } \\
\hline & 2019 Sep 25 & 2019 Sep 27 & 2019 Oct 9 \\
\hline Aedes cinereus & 1 & 2 & 0 \\
\hline Aedes japonicus & 8 & 3 & 0 \\
\hline Aedes trivittatus & 107 & 58 & 6 \\
\hline Aedes vexans & 72 & 22 & 1 \\
\hline Anopheles punctipennis & 3 & 1 & 0 \\
\hline Anopheles quadrimaculatus & 11 & 9 & 1 \\
\hline Anopheles walkeri & 1 & 0 & 0 \\
\hline Coquillettidia perturbans & 8 & 7 & 0 \\
\hline Culex erraticus & 0 & 7 & 1 \\
\hline Culex pipiens & 4 & 2 & 0 \\
\hline Culiseta melanura & 4 & 2 & 0 \\
\hline Culex territans & 0 & 1 & 0 \\
\hline Orthopodomyia signifera & 1 & 0 & 0 \\
\hline Psorophora ferox & 21 & 5 & 0 \\
\hline Uranotaenia sapphirina & 6 & 1 & 4 \\
\hline Total no. mosquitoes & 247 & 118 & 13 \\
\hline Total species & 13 & 13 & 5 \\
\hline Total no. traps & 10 & 13 & 12 \\
\hline Overnight temperature, ${ }^{\circ} \mathrm{C}$ & $16-22$ & $19-21$ & $11-18$ \\
\hline
\end{tabular}

pup 4 included thoracic rib fractures and moderate, acute, diffuse, fibrinosuppurative bacterial alveolitis and pleuritis.

We conducted mosquito surveillance throughout the zoo's property using dry ice-baited, CDC miniature light traps (John W. Hock Company, https:/ / www.johnwhock.com) on 3 different dates (September 25 and 27, October 9). Mosquitoes were identified to species, and pools of $\leq 25$ individuals were tested for EEEV RNA by rRT-PCR (15). Both the enzootic vector, Culiseta melanura ( $\mathrm{n}=6 / 378)$, and possible bridge vector mosquito species such as Coquillettidia perturbans $(\mathrm{n}=15 / 378)$ were present (Table 2$)$. After risk assessment, with local and state agencies, mosquito management was implemented on the property, including targeted barrier and state conducted adulticide spray over the area. All pools were negative for EEEV RNA.

\section{Conclusions}

Zoonotic disease detection, especially for reportable diseases, may have implications to a zoo beyond animal health and may require a substantial amount of time and resources. After diagnosis of EEEV cases, the zoo provided educational material on EEEV and complimentary DEET mosquito spray for staff and zoo patrons. In addition, all overnight camping safaris, evening events, and school field trip groups were canceled. Zoos can act as sentinels for disease detection in an area because of the wide variety of resident species and thorough necropsies. Since the diagnosis of EEEV, BPZ's preventative medicine measures to decrease the risk for nondomestic canids to contract
EEEV include the use of a monthly topical pyrethrinbased product on all Mexican wolves starting at 8 weeks of age.

Because of the natural distribution of the Mexican wolf population in Mexico and the southwestern United States, EEEV probably has little effect on the free-ranging population. However, the translocation of animals to zoos outside of their natural range may expose them to novel diseases such as EEEV. The cases in our study provide evidence for clinicians to include EEEV as a differential for acute neurologic signs or death in young canids, both domestic and nondomestic, especially during outbreaks of EEEV.

\section{Acknowledgments}

We thank the Binder Park Zoo animal care staff for their dedication in caring for these animals. We thank the staff of the Calhoun County Public Health Department, Michigan Department of Agriculture and Rural Development, and Michigan Department of Health and Human Services for their assistance during this disease occurrence.

This work was supported in part by the Centers for Disease Control project Midwest Center of Excellence in Vector-Borne Disease (contract no. U50 723K866).

\section{About the Author}

Dr. Thompson is the staff veterinarian at Binder Park Zoo in Battle Creek, Michigan, and an adjunct professor with Michigan State University College of Veterinary Medicine. Her main research interests are infectious diseases and neonatal medicine. 


\section{References}

1. Skaff NK, Armstrong PM, Andreadis TG, Cheruvelil KS. Wetland characteristics linked to broad-scale patterns in Culiseta melanura abundance and eastern equine encephalitis virus infection. Parasit Vectors. 2017;10:501. https:/ / doi.org/10.1186/s13071-017-2482-0

2. Armstrong PM, Andreadis TG. Eastern equine encephalitis virus in mosquitoes and their role as bridge vectors. Emerg Infect Dis. 2010;16:1869-74. https:/ / doi.org/ 10.3201/eid1612.100640

3. Molaei G, Armstrong PM, Graham AC, Kramer LD, Andreadis TG. Insights into the recent emergence and expansion of eastern equine encephalitis virus in a new focus in the Northern New England USA. Parasit Vectors. 2015;8:516. https:// doi.org/10.1186/s13071-015-1145-2

4. Steele KE, Twenhafel NA. Review paper: pathology of animal models of alphavirus encephalitis. Vet Pathol. 2010;47:790-805. https://doi.org/10.1177/0300985810372508

5. McBride MP, Sims MA, Cooper RW, Nyaoke AC, Cullion C, Kiupel M, et al. Eastern equine encephalitis in a captive harbor seal (Phoca vitulina). J Zoo Wildl Med. 2008;39:631-7. https://doi.org/10.1638/2008-0021.1

6. Guthrie A, Citino S, Rooker L, Zelazo-Kessler A, Lim A, Myers C, et al. Eastern equine encephalomyelitis virus infection in six captive southern cassowaries (Casuarius casuarius). J Am Vet Med Assoc. 2016;249:319-24. https://doi.org/10.2460/javma.249.3.319

7. Schmitt SM, Cooley TM, Fitzgerald SD, Bolin SR, Lim A, Schaefer SM, et al. An outbreak of Eastern equine encephalitis virus in free-ranging white-tailed deer in Michigan. J Wildl Dis. 2007;43:635-44. https://doi.org/ 10.7589/0090-3558-43.4.635

8. Tate CM, Howerth EW, Stallknecht DE, Allison AB, Fischer JR, Mead DG. Eastern equine encephalitis in a freeranging white-tailed deer (Odocoileus virginianus). J Wildl Dis. 2005;41:241-5. https://doi.org/10.7589/0090-3558-41.1.241

9. Farrar MD, Miller DL, Baldwin CA, Stiver SL, Hall CL.
Eastern equine encephalitis in dogs. J Vet Diagn Invest. 2005;17:614-7. https://doi.org/10.1177/104063870501700619

10. Andrews C, Gerdin J, Patterson J, Buckles EL, Fitzgerald SD. Eastern equine encephalitis in puppies in Michigan and New York states. J Vet Diagn Invest. 2018;30:633-6. https://doi.org/10.1177/1040638718774616

11. Carstensen M, Giudice JH, Hildebrand EC, Dubey JP, Erb J, Stark D, et al. A serosurvey of diseases of free-ranging gray wolves (Canis lupus) in Minnesota, USA. J Wildl Dis. 2017;53:459-71. https://doi.org/10.7589/2016-06-140

12. Forshey TM, Byrum BA, Machesky KD, Stephen Roney C, Gomez TM, Mitchell JR, et al.; Centers for Disease Control and Prevention (CDC). Notes from the field: multistate outbreak of Salmonella Altona and Johannesburg infections linked to chicks and ducklings from a mail-order hatchery United States, February-October 2011. MMWR Morb Mortal Wkly Rep. 2012;61:195.

13. Kiupel M, Fitzgerald SD, Pennick KE, Cooley TM, O'Brien DJ, Bolin SR, et al. Distribution of eastern equine encephalomyelitis viral protein and nucleic acid within central nervous tissue lesions in white-tailed deer (Odocoileus virginianus). Vet Pathol. 2013;50:1058-62. https://doi.org/10.1177/0300985813488956

14. Nolen-Walston R, Bedenice D, Rodriguez C, Rushton S, Bright A, Fecteau ME, et al. Eastern equine encephalitis in 9 South American camelids. J Vet Intern Med. 2007;21:846-52. https://doi.org/10.1111/j.1939-1676.2007.tb03030.x

15. Hull R, Nattanmai S, Kramer LD, Bernard KA, Tavakoli NP. A duplex real-time reverse transcriptase polymerase chain reaction assay for the detection of St. Louis encephalitis and eastern equine encephalitis viruses. Diagn Microbiol Infect Dis. 2008;62:272-9. https:/ / doi.org/10.1016/j.diagmicrobio. 2008.07.004

Address for correspondence: Kimberly A. Thompson, Binder Park Zoo, 7400 Division Dr, Battle Creek, MI, 49014, USA; email: kthompson@binderparkzoo.org 